\title{
VIRTUAL REALITY IN EDUCATION: TRENDS AND ISSUES
}

\author{
Kelvin K. Omieno \\ Department of Computer \\ Science, Masinde Muliro \\ University of Science and \\ Technology, Kenya Box 190- \\ 50100 Kakamega,
}

\author{
Franklin Wabwoba \\ Department of Computing and \\ Informatics, Kibabii University \\ College, Kenya, Box 1699- \\ 50200, Bungoma
}

\author{
Nahason Matoke, \\ Department of Computer \\ Science, Masinde Muliro \\ University of Science and \\ Technology, Kenya Box 190 - \\ 50100, Kakamega,
}

\begin{abstract}
Computer-mediated learning is becoming an increasingly common form of education in institutions of higher learning (IHL). Many IHL in developing nations, such as Kenya, have greatly experienced an increase in demand for higher education. On the other hand, the ability to connect people with required sets of skills, regardless of their location in the world has been enabled by advances in information technology over the past 20 years. Use of virtual learning systems (VLS) has rapidly emerged as a very promising technology that will probably match the innovation of technologies such as multimedia/hypermedia. These VLS have the potential to provide opportunities for active, flexible, and increasingly individualized learning experiences. It also explains virtual reality principle, describes the interactive educational environment, highlights the challenges higher education face in the traditional mode of delivery and discusses educational benefits of implementing virtual learning environments in IHL. The paper makes a number of recommendations for successful adoption of VLS in higher education
\end{abstract}

Keywords- Institutions of higher learning; virtual reality, virtual learning systems, learning and cognition, simulation;

\section{INTRODUCTION}

Our society is undergoing a process of rapid change, moving toward what is variously called the "information society", the "knowledge society", the "learning society" or "learning economy" [1]. In light of the widespread recognition of the enduring challenge of enhancing the learning of all students-including a growing number of students representing diverse racial, ethnic, and socioeconomic backgrounds - there has been an explosion of literature on teaching, learning, and assessment in higher education [2].

Information and Communication Technology has had profound impact on the way we teach and learn ([3], [4]) which have created an information revolution within an optimistic global society that has embraced virtual learning. Kenya faces challenges in her efforts to achieve her goal "education for all", as a developing country. E-learning has been suggested as an alternative approach that can overcome these challenges involved in reaching underserved students [5]. It is therefore important for an institution to know if it is ready for computer-mediated learning.

Virtual Reality (VR) is a computer-based technology that provides visual, aural and tactile stimuli of a virtual world generated in real time. A virtual learning environment (VLS) is a set of integrated teaching and learning tools designed to enhance a student's learning experience [6].
Over the last decade, a number of VLS have been developed and adopted by industries, universities and even high higher education. The VR technology came up from forty years of development in areas such as computer science, electronics and psychology. The advent of web 2.0 tools has stimulated a drift in the way learning and teaching is offered due to its flexibility and interractiveness ([7], [8], [9]). VLS platform models real-world education by integrating a set of equivalent virtual concepts for tests, homework, classes, classrooms, and so on, and perhaps even museums and other external academic resources [10]. Though VLS is heavily applied in distance learning, it has now often been used to supplement traditional face to face classroom activities, commonly known as Blended Learning. The VLS systems usually run on servers, to serve the course to students Multimedia and/or web pages.

Virtual reality and by extension VLS is breaking out from traditional areas of use (e.g. aviation industry and research) and now emerging as an increasingly important tool for education and training ([7], [11]). Part of the reason is that as the cost of computing power decreases it is becoming an economically viable media. However, economics alone do not fully account for the emergence of VLS growing incorporation in education (at all levels ranging from first grade through graduate education) and training. Why is the use of virtual objects and learning becoming so important? VLS:

a) Are applicable to students of all levels and ages.

b) Help students see complex relationships that would otherwise involve expensive equipment or dangerous experiments.

c) Allow for math, science, and technical skills to be taught in an applied, integrated manner.

d) Provide students with new methods of problem solving.

e) Provides realistic training and skills for a multitude of career areas. It is used extensively in science and industries.

f) Are cost effective and reduces risks to humans.

g) Facilitate the integration of distance and campusbased learning or of learning on different campuses.

h) Economize on the time of teaching staff, especially when they are also involved in research and administration. Through use of VLSs there is less time used and produces more professional products.

There has been an increased demand for higher education while at the same time been inadequacy in funding for IHL due to harsh economic challenges. This has triggered a number of these countries to adapt alternative teaching and learning approaches such as online education ([12], [7]). However, there still remains a gap. 


\section{RESEARCH DESIGN}

A descriptive survey approach was adopted including extensive literature survey and online interviews. Research findings on VLS adoption offer some guidance, with researchers focusing on either student's acceptance by measuring their computer efficacy levels or use-intentions or their resistance by measuring their supporting/resisting behaviors. In doing so, "acceptance" and "resistance" have, implicitly or explicitly, been conceptualized as either/or proposition, the opposite ends of a single closed dimension. 42 students were interviewed The researcher explored six actor groups in adopting VLS and used six-group model as depicted in Fig. 1. The responses by students are captured and summarized as illustrated in Fig. 2.

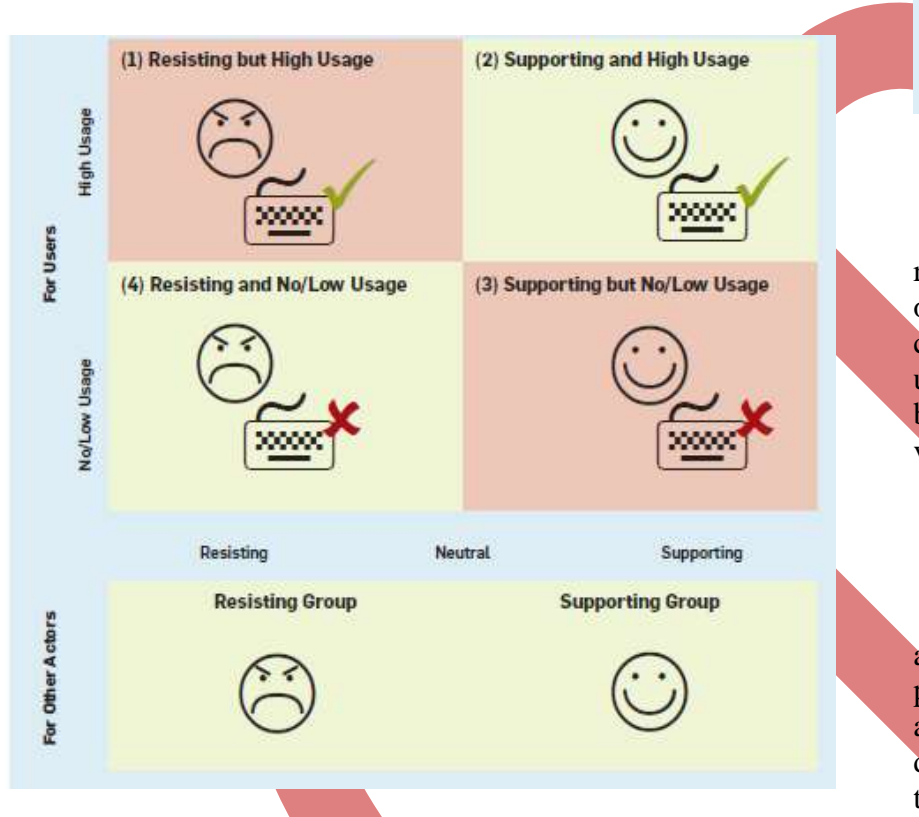

FIGURE 1: SIX-ACTOR GROUPS IN ADOPTING VLSS IN HIGHER EDUCATION

Fig. 2 gives summary of student responses in relation to VLS and adoption. Most students are very positive about usage of virtual reality tools in higher education for teaching and learning. However, they also point out a number of challenges as depicted from Fig. 2

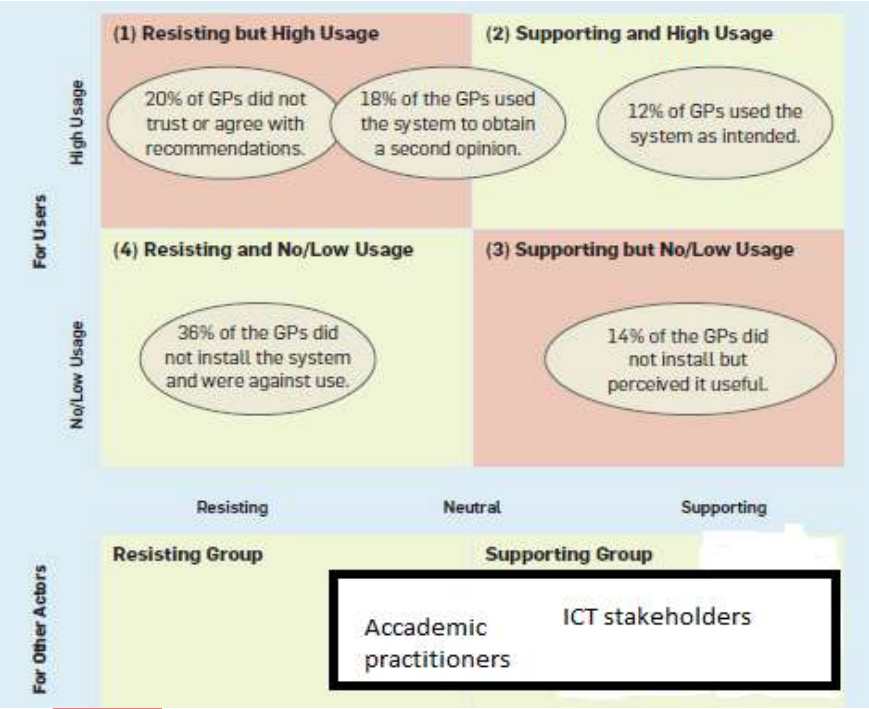

FIGURE 2: RESPONSES BY STUDENTS ON VLSS ADOPTION

From the results in Fig. 2 it's clear that it's not only resistance to usage of VLSs that can affect negative adoption of VLSs in higher education but also a number of factors come in to play. There are those who support but with no/low usage and hence there must be proper strategies that ought to be embraced in order to maximize the adoption of VLSs and virtual objects in higher education.

\section{VLS IN EDUCATION AND TRAINING}

There has been a lot of research on alternative approaches to teaching and learning. However, as practitioners and researchers have found, there are challenges associated with working across time, space and cultural dimensions. Not only does technology need to be suitable to the needs of collaborating virtual team and the organization, the team must also be allowed to find its own identity and there must be a strong sense of trust between team members to bridge the dimensional gaps ([13], [14], [15]). In fact, there have been an outpouring of popular and scholarly literature about the use of computers in the workplace and how these emerging technologies can help promote collaborative work in groups by compressing space and time ( [15], [16]-[19]).

The virtual experiments do not only aim at mediating theoretical knowledge but also at introducing into practical experimental work. Users can develop experimental designs for the different learning experiments. For example, users are shown how to use control groups or how to think about adequate test situations. After an experimental design is prepared, the experiment can be performed virtually as can be depicted from Figure 3 and Figure 4. Figure 3 indeed has stepby-step demonstrations where students are guided on how to conduct practical. 


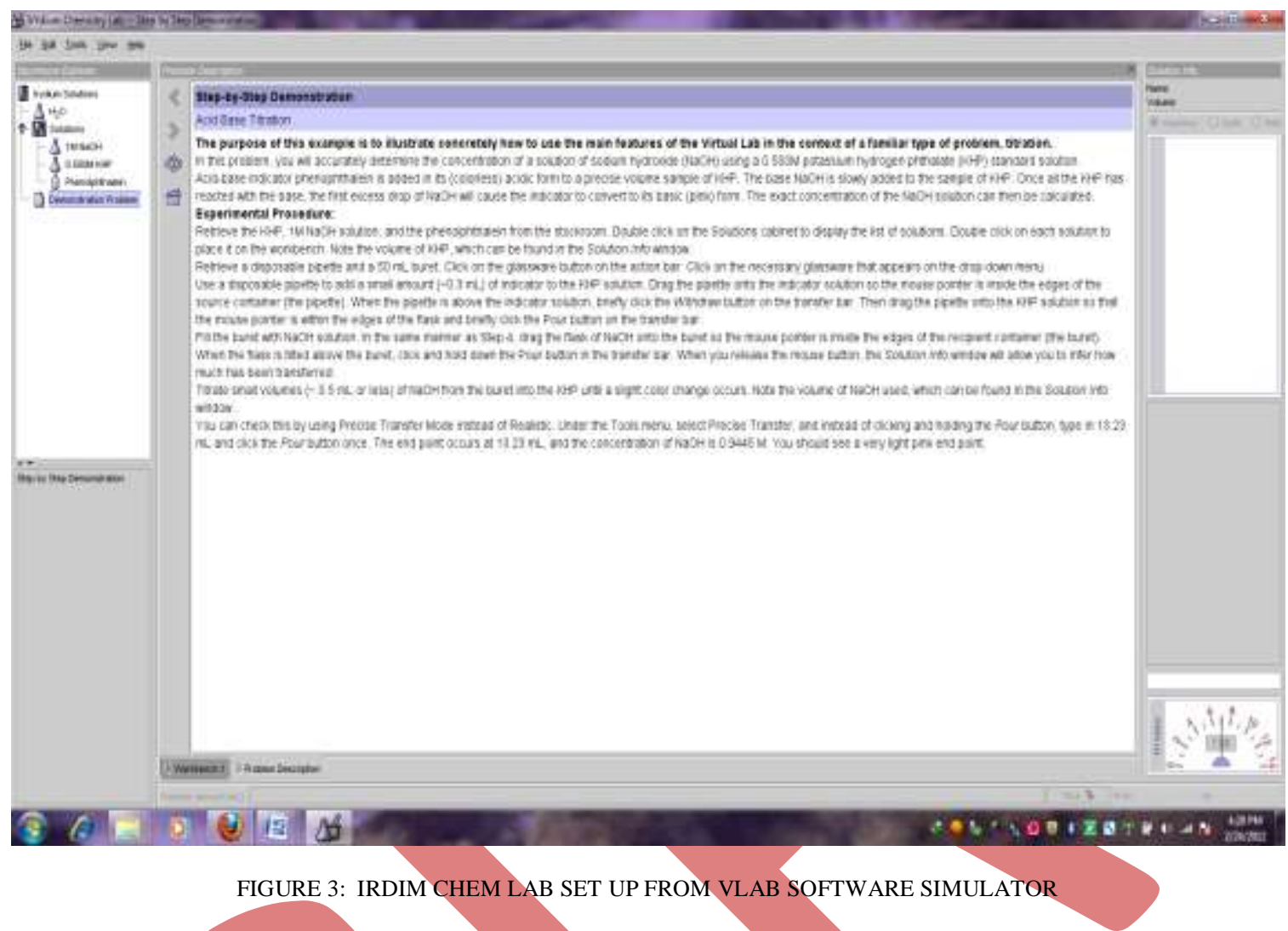

Fig. 4 depicts an example of a simulation a chemistry lab. It is a chemistry construction kit that provides students with equipment and materials such as Bunsen burners, chemicals, and a wide variety of meters and gauges and virtually all the apparatus required to set up any kind of experiment. Using these components, students perform experiments, gather and graph data, and learn about new concepts in interactive and dynamic lessons.

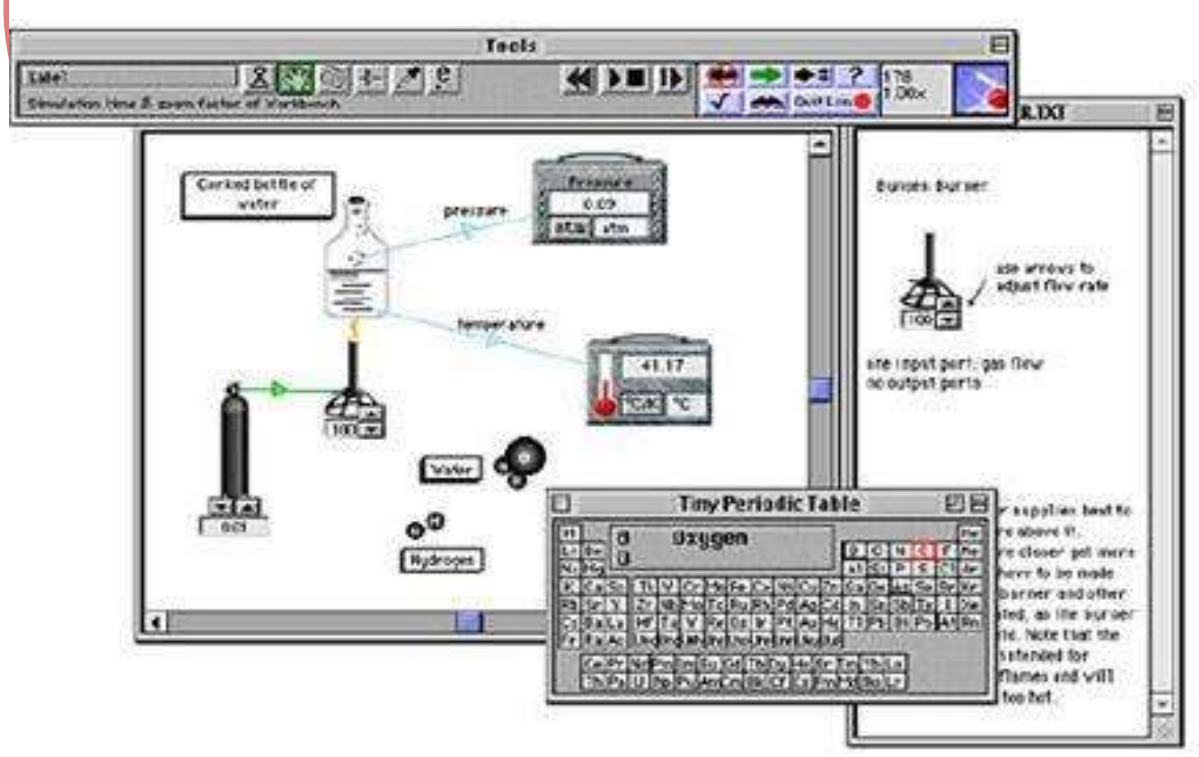

FIGURE 4: ACTIVCHEMISTRY VIRTUAL LAB SIMULATOR

\section{EDUCATIONAL BENEFITS}

\section{OF VLS}

There has been a global massification of higher education since the late 20th century. For example, in 2000, the total enrolment of higher education institutions worldwide was about 100 million, 200 times more than the global enrolment as recorded at the beginning of the 20th century ([20], [26]). Enrolments in the higher education sector in
Kenya have increased over the past twenty years [21]. At the same time demand for higher education is on increase where some of the students being mature age and working full- or part-time and the upward trend due to government policy on making education accessible and affordable for all. 
On the other hand, students using traditional instructional learning environment are expected to learn by assimilation, e.g. by listening to a lecture or reading a book on a given subject. However, several authors argue that this notion is not feasible in certain situations. Dede et. al. [22] argues that mastery of abstract science concepts requires learners to build mental models about phenomena that often must incorporate invisible factors that represent intangible concepts, items and abstractions. One problem involved in doing this is that students generally lack real-life analogies on which to build these mental models, simply because there are no such events that can be perceived in the world as we know it. Because of that, learners cannot draw on and relate to personal experiences for these phenomena.

From Fig. 4 there are a number of advantages from the use of simulation as compared with real equipments. These advantages include safety (experiments can be done that would be too dangerous for most chemistry labs), economy (saves the cost of expensive equipment and materials), and learning efficiency (students using the program are not under the time pressures often found in standard chemistry lab periods and often complete exercises at a faster rate). In addition, through VLS students are enabled to explore new concepts and gain an understanding of the interplay between related complex phenomena [23]. PC-based simulations are typically interactive and grounded in some objective reality [24].

Modularly designed programs work as a standalone educational tool, as a classroom supplement or as a study aid. In an initial stage of integration, as with the science subjects, virtual reality is best used as a supplement to existing coursework, allowing instructors to integrate the programs into learning objectives. Virtual reality and use of VLS is a giant step towards "perfect learning" - a learning environment that focuses on the student rather than placing burdens on teachers [26]. It creates a learning environment where students explore, discover and make decisions, while teachers assist and guide. From a teacher's perspective, virtual reality creates a structured environment that focuses students on specific learning objectives, similar to good teaching. Students are totally focused with no unruly behaviorThe relevance of VLS can thus be summarized in three broad areas:

i) Accessibility- If taking an Asynchronous curriculum, student has the availability to access the course after office hours. For Synchronous and Asynchronous instruction, the student has the flexibility of being in the safety of their own home.

ii) Interactivity- There is much evidence to show that students benefit from actively engaging with their course [23]. More specifically, the advantages relate to feedback, practice and customization. iii) Communication-This element is must be increased in a VLS. It helps the student to feel part of a learning community. Tools used are bulletin boards, being able to "play-back" a session, chatting, email, and instruction \& announcements are current due to the live instructor[25]

A VLS should make it possible for a course designer to present to students, through a single, consistent, and intuitive interface, all the components required for a course of education or training. When implementing VLS, several considerations have to be made which include but not limited to the following elements:

a) The syllabus for the course

b) Administrative information including the location of sessions, details of pre-requisites and co-requisites, credit information, and how to get help

c) A notice board for up-to-date course information

d) Student registration and tracking facilities, if necessary with payment options

e) Basic teaching materials. These may be the complete content of the course, if the VLS is being used in a distance learning context, or copies of visual aids used in lectures or other classes where it is being used to support a campus-based course.

f) Additional resources, including reading materials, and links to outside resources in libraries and on the Internet.

g) Formal assessment procedures

h) Electronic communication support including e-mail, threaded discussions and a chat room, with or without a moderator

i) Differential access rights for instructors and students

j) Production of documentation and statistics on the course in the format required for institutional administration and quality control

k) All these facilities should be capable of being hyperlinked together

1) Easy authoring tools for creating the necessary documents including the insertion of hyperlinks though it is acceptable (arguably, preferable) for the VLS to be designed allowing standard word processors or other office software to be used for authoring.

However, there are a number of strategies that ought to be adopted so as to maximize usage of VLS. Table 5 shows various strategies that can be used to promote VLS adoption in IHL.

\begin{tabular}{lll}
\hline & 1. Resisting but High usage of VLS & 2. Supporting and High usage of \\
High Usage of VLSs & - Cultural resistance; building & VLS \\
(For teaching \& learning) & dialogue, training & - Inquire why users like VLSs \\
& - Fear of losing power and & then apply to answers to retain \\
& autonomy; negotiation & them \\
& - Fear of uncertainty; explanation & -Empower and encourage users \\
& & here to be ambassadors \\
\hline
\end{tabular}




\begin{tabular}{|c|c|c|}
\hline $\begin{array}{l}\text { No/ Low Usage of VLSs } \\
\text { (For teaching \& Learning) }\end{array}$ & $\begin{array}{l}\text { 3. Resisting and No/Low Usage } \\
\text { - Try to move users to group of } \\
\text { supporting-and- high usage; it's very } \\
\text { expensive and risky } \\
\text { - Recommended to move users in this } \\
\text { group first to supporting-but-no/low } \\
\text { usage } \\
\text { - Attempt to force users to Resisting- } \\
\text { but-high usage }\end{array}$ & $\begin{array}{l}\text { 4. Supporting but No/Low usage } \\
\text { - Encourage/ inspire users here by } \\
\text { asking technology-related issues } \\
\text { - Training users; tech-support desks } \\
\text { required } \\
\text { - More support to the users } \\
\text { including: financial subsidies and } \\
\text { related demands }\end{array}$ \\
\hline $\begin{array}{l}\text { Other Actors } \\
\text { (Including government/ } \\
\text { Management of IHL }\end{array}$ & $\begin{array}{l}\text { Resisting Group } \\
\text { - Minimize political conflict; } \\
\text { - Find mutual benefits of CML } \\
\text { technologies }\end{array}$ & $\begin{array}{l}\text { Supporting Group } \\
\text { - Build partnership with this group; } \\
\text { - Work together with them to } \\
\text { eliminate non-technical issues }\end{array}$ \\
\hline
\end{tabular}

TABLE 5: STRATEGIES TO PROMOTE VLSS IN IHL

\section{CONCLUSION}

The researchers strongly believe that the use of VLS and VR in higher education using distributed computing infrastructures provides viable platform and a new regime of time-to-solution. This will stimulate innovation and cost-effective but at the same time offer quality education. VLS and use of virtual reality can be employed in virtually all areas of study. Application of

\section{REFERENCES}

[1]. Sirje Virkus, Lawraine Wood, (2004),"Change and innovation in European LIS education", New Library World, Vol.105 Iss: 9 pp. 320 - 329

[2]. Clifton F. C, Jason J. \& Gupta D (2007) Teaching-forLearning (TFL): A Model for Faculty to Advance Student Learning. Innov High Educ (2007) 32:153-165

[3]. Omwenga E. (2011). Modelling a Computer-mediated Learning Infrastructure: Concepts, Principles and Implementation Requirements. Lambert publishers ISBN10: 3845408588

[4]. Lai, K. W., Khaddage, F. \& Knezek, G. (2011). Blending student technology experiences in formal and informal learning. Paper submitted to Journal of Computer Assisted Learning

[5]. Omoda-Onyait G. \& Lubega J. (2011) E-learning Readiness Assessment Model: A Case Study of Higher Institutions of Learning in Uganda. Hybrid Learning Lecture Notes in Computer Science, 2011, Volume $6837 / 2011$, 200-211, DOI: 10.1007/978-3-642-22763$9+19$

[6]. Laws, A.G., Forsyth, H.L. \& Baskett, M. (2009). MUVE, the Future of e-Learning: Building a Virtual Learning World . Proceed. of second International Conference on developments in eSystems Engineering (DESE). Page(s): $307-313$

[7]. Dede, C., Nelson, B., Ketelhut, D. J. and Bowman, C. (2004) Design-based research strategies for studying situated learning in a Multi-User Virtual Environment. 6

[8]. Dickey, M. D. (2003) Teaching in 3D: Pedagogical affordances and constraints of 3D virtual worlds. Distance Education 24:1, pp. 105-121.

[9]. Alexander, B. (2006) Web 2.0: A new wave of innovation for teaching and learning?. EDUCAUSE Review 41:2, pp. 32-44.

[10]. Meneses, G.A.,'Design of an electronic instrumentation virtual laboratory based on free-open resources", Computing Congress (CCC), 2011 6th Colombian, On page(s): 1 - 6, Volume: Issue: , 4-6 May 2011

[11]. Callaghan, M.J. McCusker, K. Lopez Losada, J. Harkin, J.G. \& Wilson, S.(2009). Integrating virtual worlds \& virtual learning environments for online education. Proceed. of International IEEE Consumer Electronics simulation includes areas such as: computational chemistry, materials science, molecular biology and environmental chemistry. Enabling and accelerating the transition of teaching and learning to VLS will make students be more competitive, innovative and costeffective to higher education.

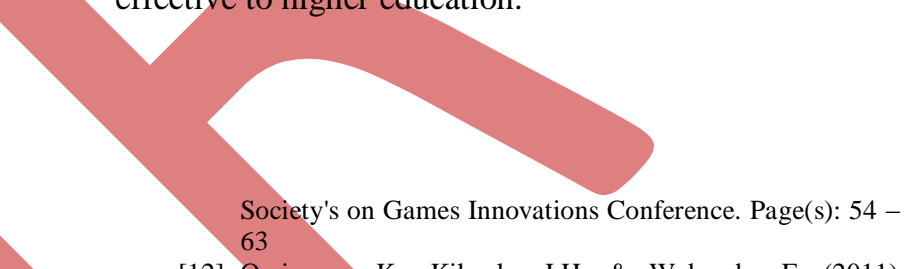

[12]. Omieno, K., Kilwake J.H. \& Wabwoba F. (2011) Promoting Quality Outcomes in Higher Education using new Learning Technologies. Journal of Education and Social Sciences. ISSN:2223-490X,Vol. 1. No.1. Pp: 145151

[13]. Millward, L. J., \& Kyriakidou, O. (2004). Effective Virtual Teamwork: A Socio-Cognitive and Motivational Model. In S. H. Godar \& S. P. Ferris (Eds.), Virtual and Collaborative Teams: Process, Technologies and Practice (pp. 20-34): Idea Group Publishing

[14]. Mitchell, A., \& Zigurs, I. (2009). Trust in Virtual Teams: Solved or Still a Mystery? The DATA BASE for Advances in Information Systems, 40(3), 61-83

[15]. Zornoza, A., Orengo, V., \& Peñarroja, V. (2009). Relational capital in virtual teams: the role played by trust. Social Science Information, 48(2), 257-261

[16]. Dix J, Teaming with technology, Network World 11 (2), 1994, pp. SS8-SS16.

[17]. Cohen, L. and Manion, L. (1994). Research Methods in Education. (4th ed.).London: Routledge

[18]. M. O'Hara-Devereaux, R. Johansen, Globalwork: Bridging Distance, Culture, and Time, Jossey-Bass, San Francisco, CA, 1994

[19]. Steinkuehler, \& Williams (2007). Where Everybody Knows Your (Screen) Name: Online Games as "Third Places". 1-26.

[20]. Guri-Rosenblit, S., Sebkova, H. \& Teichler, U. (2007). Massification and diversity of higher education systems: Interplay of complex dimensions. Higher Education Policy, 20(4), 373-389.

http://dx.doi.org/10.1057/palgrave.hep.8300158

[21]. MOHEST

http://www.scienceandtechnology.go.ke/index.php/downlo ads-1/cat_view/26-service-charter on 11th June 2012

[22]. Dede, C., Salzman, M., Loftin, R. B., Ash, K. (1997) "Using Virtual Reality Technology to Convey Abstract Scientific Concepts", in "Learning the Sciences of the 21st Century: research, Design and Implementing Advanced Technology Learning Environments", edited by Jacobson, M.J.,Kozma,R.B.,Lawrence Erlbaum. 
Council for Innovative Research www.cirworld.com

[23]. Peter J. K. \&.Westerlund K.K. (2009). SIMULATION IN EDUCATION AND TRAINING. Proceedings of the 2009 Winter Simulation Conference M. D. Rossetti, R. R. Hill, B. Johansson, A. Dunkin and R. G. Ingalls, eds.

[24]. Virtual Experiments,

http://www.mse.mtu.edu/outreach/virtualexperiments.html Accessed 3rd March, 2011
International Journal of Computers \& Technology Volume 4 No. 1, Jan - Feb, 2013

[25]. Enhancing Learning, http://www.ukcle.ac.uk/resources/enhancing-learningthrough-technology/using-the-VLS/ Accessed 23rd January, 2011

[26]. McGrath J. E, \& Hollingshead A.B, Groups Interacting with Technology: Ideas, Evidence, Issues, and an Agenda, Sage, Thousand Oaks, CA, 1994

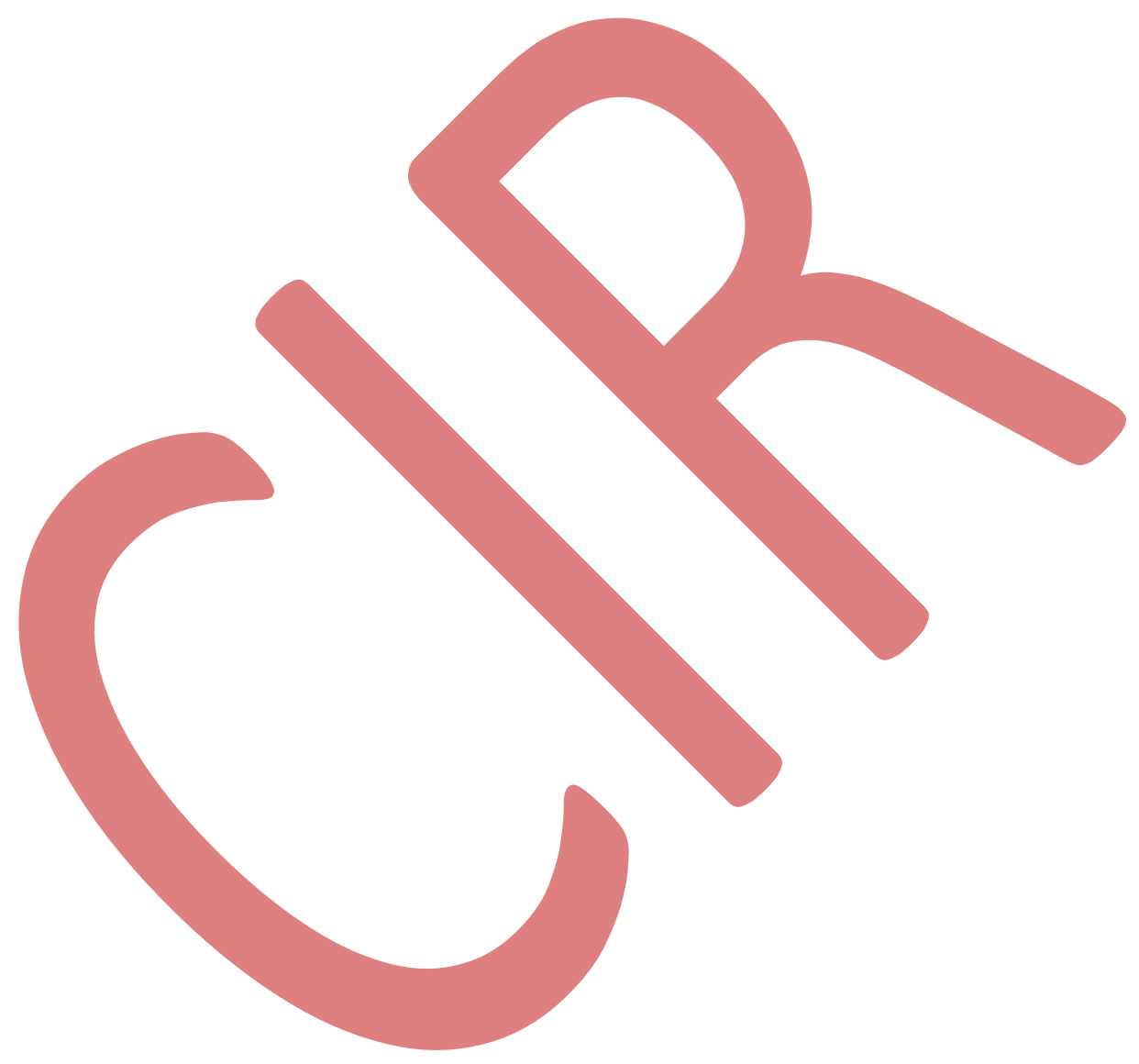

